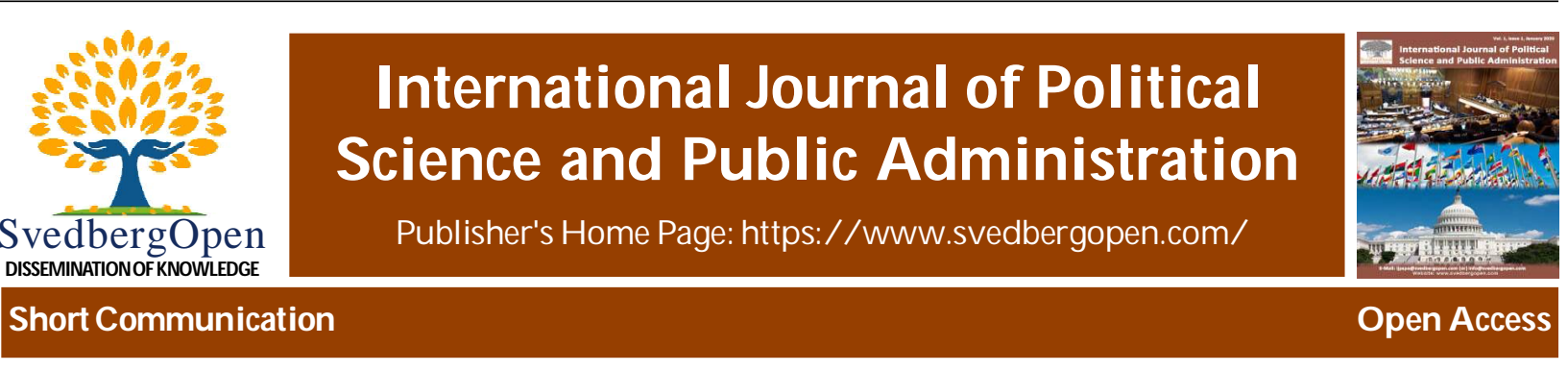

\title{
Power in international relations: with special reference to soft power
}

Dip Mala Chapagain ${ }^{1 *}$

${ }^{1}$ Department of International Relations and Diplomacy, Tribhuvan University, Kirtipur, Nepal. E-mail: chapagaindipmala@gmail.com

\section{Article Info}

Volume 1, Issue 1, June 2021

Received : 25 November 2020

Accepted : 27 April 2021

Published : 05 June 2021

doi: 10.51483/IJPSPA.1.1.2021.26-30

\begin{abstract}
The global-political history shows that countries have always been competing amongst and against one another for power. The paper briefly defines the concept of power; tries to analyze the means and their effects in shaping the capacity of an actor to exercise power; and tries to access the relevance of power in international relations. Moreover, the paper distinguishes soft power from hard power and goes further to analyze the aspects central to the constituting of soft power. The researcher has consulted books and journals in the related subject for the research. The researcher's analysis shows that, in soft power, it is necessary to value other's emotive factors rather than laying emphasis just on tangible resources that one has. The researcher has then built upon the concept of appealing notable presence as the central element in soft power and concluded by defining soft power on the
\end{abstract} premises built in the paper itself.

Keywords: International relations, soft power, Political history, Power

(c) 2021 International Journal of Political Science and Public Administration. This is an open access article under the CC BY license (https://creativecommons.org/licenses/by/4.0/), which permits

unrestricted use, distribution, and reproduction in any medium, provided you give appropriate credit to the original author(s) and the source, provide a link to the Creative Commons license, and indicate if changes were made.

\section{Background}

The notions of hierarchy and power have always been central to International Relations. The competition of countries amongst and against one another for power is evident from the World Wars that human history has witnessed.

And even though the institutionalization of the United Nations has limited physical wars between countries in the aftermath of the Second World War, countries still aspire to retain their status quo or to increase their power in the global affairs. The contemporary discourse of power looks into the role of ideas and ideologies in power acquiral, in addition to the traditional means of warfare.

\section{Objectives}

To understand the concept of power,

To access relevance of power in international relations,

To distinguish between hard power and soft power,

To define soft power by identifying the factors central in constituting it.

\section{Limitations}

The study has only used the primary mode of data collection.

The study has only used descriptive research analysis modality.

\footnotetext{
* Corresponding author: Dip Mala Chapagain, Department of International Relations and Diplomacy, Tribhuvan University, Kirtipur, Nepal. E-mail: chapagaindipmala@gmail.com
} 


\section{Introduction}

\subsection{Power in international relations: The ways of its practice}

\subsubsection{The concept of power}

While making its presence felt in every possible social relationships ${ }^{1}$, the term 'power', within a social relationship, means any chance, to carry out one's own individual or collective will, against any likely resistances. ${ }^{2}$ These possible resistances are often the wills of others. So such subjugation of others' wills against one's wills seems to imply the subjugator's control over the life chances of others. ${ }^{3}$ At the same time, an actor's ability to control the life chance of others indicates the actor's relative superior position. ${ }^{4}$ Therefore, the position of superiority (effect) and the ability to control (capacity) seem to always revolve in a loop, as shown in the figure below.

Since these effects shape the capacities of actors to determine their circumstances and fate, power deals about the phenomena of the production of these effects in and through social relations. ${ }^{5}$

Thus, an actor is said to have power against someone if there is a likelihood of willing or unwilling compromise of interests of such someone against the actor's interests.

\begin{tabular}{|l|}
\hline $\begin{array}{c}\text { Superior position } \\
\text { (EFFECT) }\end{array}$ \\
\hline \\
Figure 1: Cycle of elements of power \\
(CAPACITY)
\end{tabular}

\subsubsection{Power in international relations}

Like in all social sciences, the concept of power is central to international relations, and is in fact, the prime determinant of a country's standing in international politics.

As studied earlier, power deals with the production of effects, in and through social relations, that shape the capacities of actors to determine their circumstances and fate. To understand what kind of means and their effects shape the capacities of an actor to exercise power, let us take this classroom analogy as given below.

\section{The classroom analogy of exercise of power:}

We usually see that these following sets of students are more likely to dominate the classroom with their presence either in informal or formal settings.

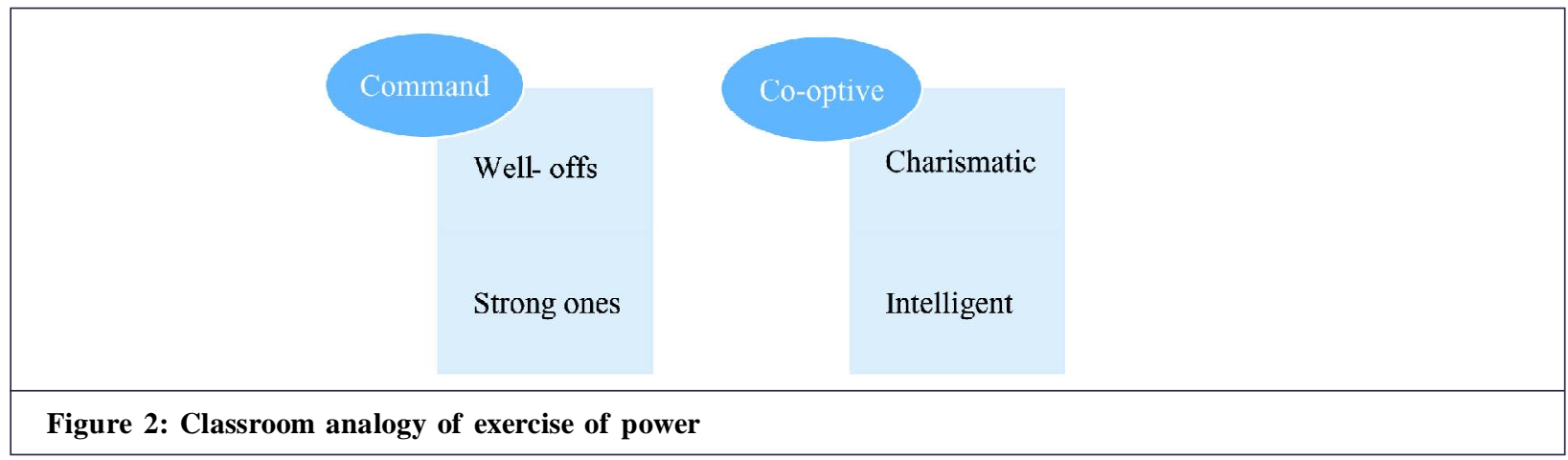

2 Wallimann, I \& Tatsis, N., On Max Weber's Definition of Power, Sage Journals, Volume 13 Issue 3, December 1977, availbale in: https://journals.sagepub.com/, accessed date: January 2, 2020

3 Mayer, Kurt Bernd. (1955). Class and society. New York : Random House p 26. "Sociologically, power refers to the control which certain groups and individuals are able to exercise over the life chance of others".

4 Nelson W. Polsby. (1980). Community power and political theory : a further look at problems of evidence and inference. 2nd edition, Yale University and Press. New Haven and London. p 104.

5 Barnett, M., \& Duvall, R. (2005). Power in International Politics. International Organization, 59(1), 39-75. Retrieved August 14, 2020, from www.jstor.org/stable/3877878 
1. Well-offs through treats (inducement).

2. Strong ones through bullying (coercion).

3. Charismatic ones through attraction.

4. Knowledgable/Intelligent ones through knowledge/manipulation.

All these sets of students are alike in a way that all of them; (i) can achieve the same purpose, and (ii) by affecting the behavior of others.

However, the means to achieve their common end of classroom domination can be categorized under two heads based on the nature of their behaviors, as shown in the figure.

Command power operates through resources like coercion or inducement, and it generally implies the ability to change what others do. ${ }^{6}$ In International Relations, hard-power resources usually associate with command behavior. ${ }^{7}$

Co-optive power operates mainly through resources like attractiveness of oneself or manipulation, and it generally implies the ability to shape what others want. In International Relations, soft-power resources usually associate with cooptive behavior. ${ }^{8}$

So in the relation between two countries, hard power of one state against the other can be gained as a virtue of "one's" might, while the state can gain soft power by tapping into "other's" emotion or reason.

\section{Soft Power}

Unlike in hard power, the modes used by soft power to accrue power are intangible. The reason behind the idea of soft power gaining more receiving more attention over hard power in the recent times is the fact that international laws have now limited the capacity capacity of states for overt engagement in physical wars. The international relations in the past, dominated by the realist theory emphasized primarily on the military power as means of security and survival for states in the self-help world. ${ }^{8}$ Now, with the invent of information revolution ${ }^{9}$, and with the emergence of multilateral organizations, the world has become more interconnected and interdependent. ${ }^{10}$ And in this type of global setting, the neoliberals argue that the use of force as a policy option becomes less significant for the states. ${ }^{11}$

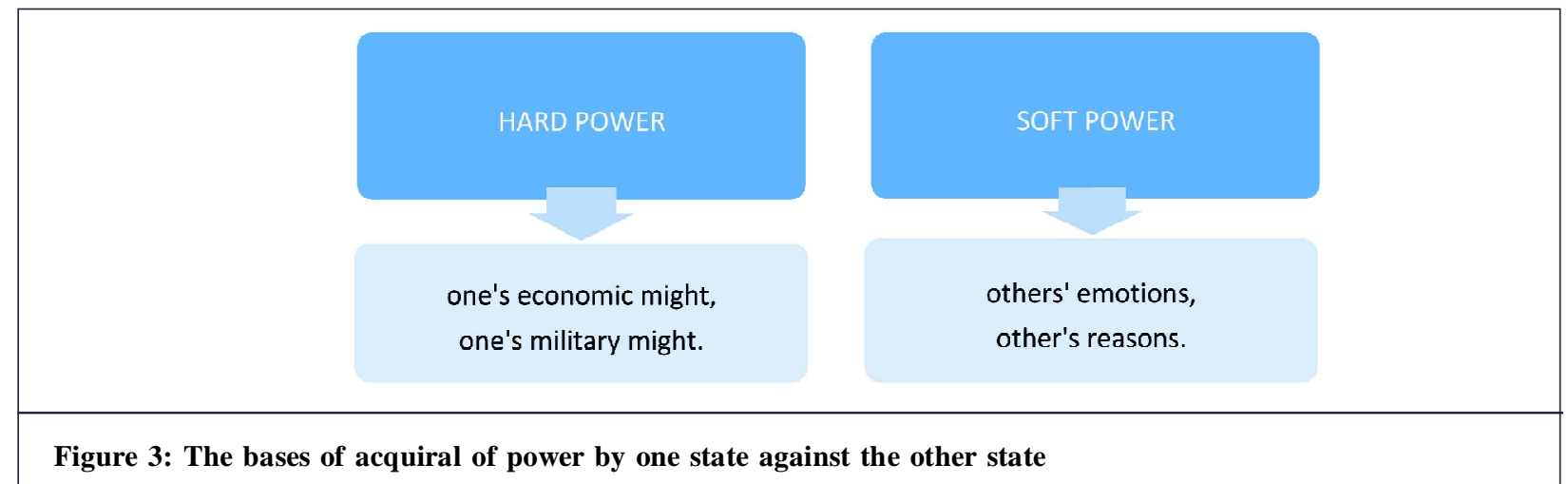

The relative domination of an actor over any matter is reflective of its power in such matter. The institutionalization of the United Nations and the body of international laws, has led us to distinguish between the modes of power acquiral as fair and foul, the question of which was irrelevant in the earlier times. So today, every means used by states to gain this relative domination in a certain matter in global affairs is scrutinized under international laws. Such scrutiny has necessitated the states to make their presence felt in the international community, by legitimate ways and actions.

Moreover, the more one can make their presence felt in the international community by legitimate ways and actions, and in ways that other countries look up to, for example, developmental and economic progress in the country, the more one seems to have tapped the emotion or reason of their global counterparts. This process of being able to tap into other's emotions and their reason is the first step in making others attracted to one's being.

\footnotetext{
Jr., J. N. S. (2005). Soft Power: The Means To Success In World Politics (New Ed). PublicAffairs. P 7

Id., p 5 : "Hard power can rest on inducements ("carrots") or threats ("sticks")." 8 Id., P 7

Heywood, A. (2011). Global Politics (Macmillan Foundations Series) (1st ed.). Springer. P 213

9 Keohane, R., \& Nye, J. (1998). Power and Interdependence in the Information Age. Foreign Affairs, 77(5), 81-94. doi:10.2307/ 20049052

10 Heywood, A. (2011). Global Politics (Macmillan Foundations Series) (1st ed.). Springer. P 21412 Ibid.

11 Jr., J. N. S. (2005). Soft Power: The Means To Success In World Politics (New Ed). PublicAffairs. P 614 Id., P 7
} 


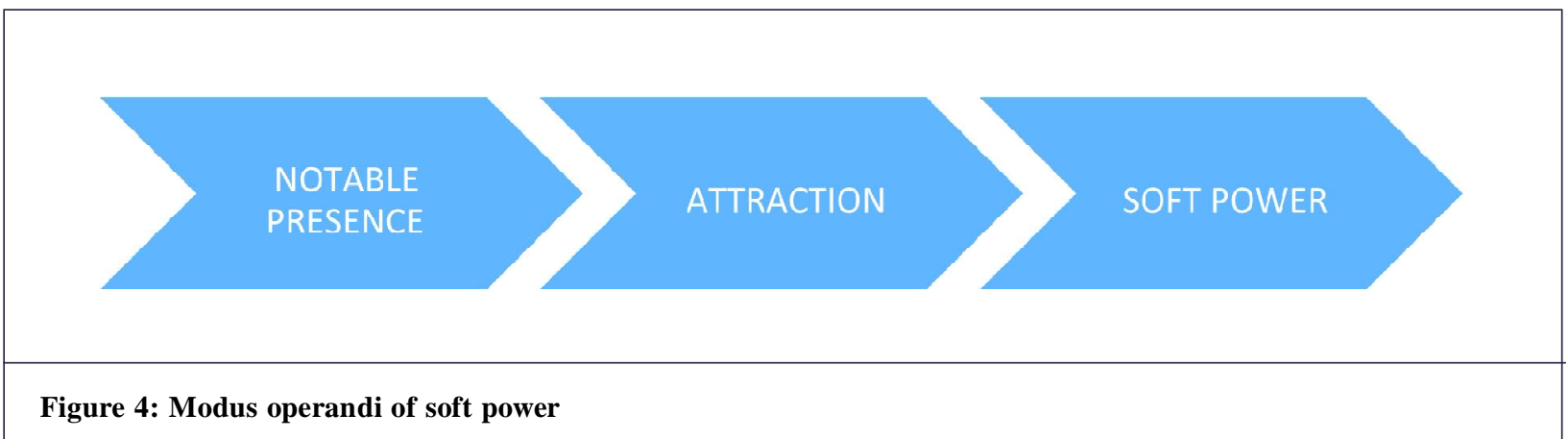

The power that comes from attraction has been understood for long, and likewise is the fact that it costs less to lead by successful representation the values that others want to follow. ${ }^{12}$ As Joseph Nye (2005) states, "Soft power uses a different type of currency (not force, not money) to engender cooperation-an attraction to shared values and the justness and duty of contributing to the achievement of those values" ${ }^{13}$ (p.5). A country is a successful propagator of soft power when it can shape the decisions of its counterparts for ideas, in a way that invisible hands, as Adam Smith tells, shapes the decisions of people in a free market. ${ }^{14}$ This ability of making others want to do what you want them to do, without having to use carrots or sticks for making them do it, is what we can term as soft power. ${ }^{15}$

So in behavioral terms, soft power is attractive power ${ }^{16}$, because it coopts rather than coercing one's counterparts ${ }^{17}$. In terms of resources, soft power resources are the assets that produce such attraction. ${ }^{18}$

In any situation where an actor desires certain outcomes, the most fundamental consideration is whether there are desired resources. At the same time, it has to be understood that potential power resources do not always translate into realized power. ${ }^{19}$ For the achievement of desired outcomes, the objective measure of potential soft power has to be attractive in the eyes of specific audiences, and that attraction must influence policy outcomes. ${ }^{20}$ The ability to posit attractiveness/appeal on one's notable presence depends significantly on its expressional, functional, and behavioral aspects. For example, a country with a strong military base certainly makes its presence notable in the globe. But whether such presence is appealing or repelling for other global counterparts is another question. The form of notable presence, which is appealing to others, is the subject matter of soft power. Mentioned below are the aspects of the expression of appealing notable presence; the factors ${ }^{18}$ they are concerned with, and how those factors help shape such appealing notable presence.

\subsection{Aspects of expression of appealing notable presence}

1. Identity aspect

The identity aspect is concerned with how a country, through its culture, expresses its values. The way to use the identity aspect in favor of appealing notable presence is by prioritizing the values that are attractive to others, or in other words, the values that are shared by them. When values are shared, countries will willingly want to join hands with you to meet your objectives, which seems to them as theirs as well.

2. Functional aspect

The functional aspect is concerned with how a country functions in domestic and foreign spheres, and the examples it sets in its actions. The way to use the functional aspect in favor of appealing notable presence is by continually upholding or living up to the values that the country says it has. Living up to one's said values conveys the credibility of the country in the eyes and minds of the foreign counterparts. Further, this also communicates among

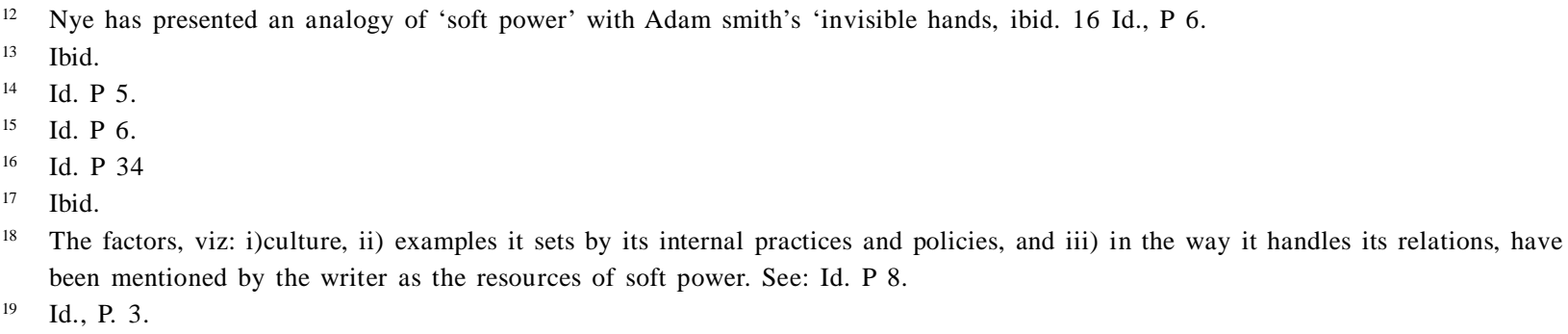




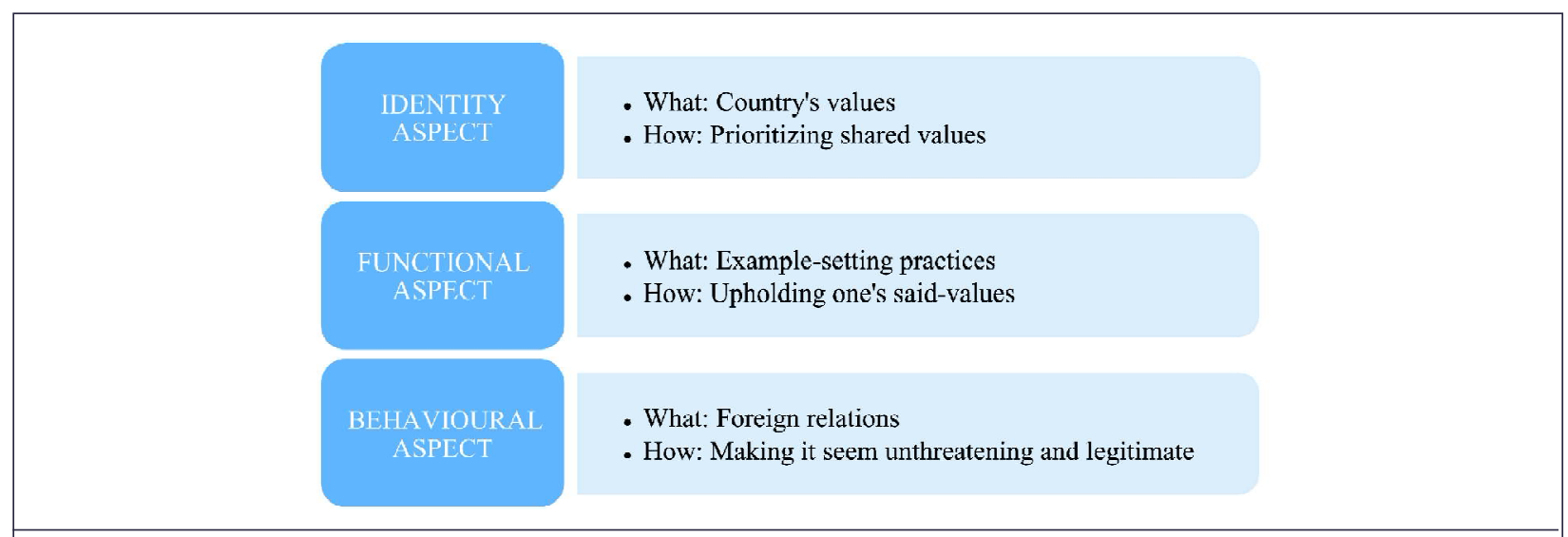

Figure 5: Factors shaping different aspects of the appealing notable presence

them, the possibility of willingness to comply for the achievement of shared objectives, if any, and of the possible nature of relation, they might want to share.

3. Behavioral aspect

The behavioral aspect is concerned with how a country handles its relations with other states. The way to use the behavioral aspect in favor of appealing notable presence is by making such relation seem unthreatening and legitimate. The foreign relations handled by a country seem unthreatening to its counterparts when the nature of such relations align with the interests that the other country shares and aims to uphold. Such alignment of interests assures the foreign counterparts of the possibility of the continuance of the particular nature of the relationship they share. This then convinces them to strive together for the achievement of such shared objectives.

Therefore, in a way, this idea of appealing notable presence functions just like the pre-affair phase between couples. At first, your actions get you noticed because of the way they manage to seduce your likely partner. After that, you come into their thoughts, and they start analyzing the likelihood of their compatibility with you, based on your attributes that they have noticed. After having taken repetitive notice of you, and getting assured that you behave in a certain way, which is held appropriate by them, it is when they get attracted to you.

When they get attracted to you, you become their ideal. This means that the foreign counterparts will then be willing to compromise some part of their individuality for the attainment of your goal, which they now give the name of a shared objective. The rest is history.

Therefore, we can sum up soft power as the expression of oneself in a way that posits unthreatening attraction to one's values and systems, so that others willingly interact and engage with you for the collective achievement of objectives that you have set.

\section{References}

Bierstedt, R. (1950). An analysis of social power. American Sociological Review, American Sociological Association. 15(6).

Wallimann, I. and Tatsis, N. (1977). On Max Weber's definition of power, Sage Journals, 13(3). From https:// journals.sagepub.com/

Mayer, Kurt, Bernd. (1955). Class and society. New York : Random House.

Nelson, W. Polsby. (1980). Community power and political theory: A further look at problems of evidence and inference. 2nd edition, Yale University and Press. New Haven and London.

Barnett, M. and Duvall, R. (2005). Power in international politics. International Organization. 59(1), 39-75. from www.jstor.org/stable/3877878

Jr., J. N. S. (2005). Soft Power: The Means To Success In World Politics (New Ed). PublicAffairs.

Heywood, A. (2011). Global Politics (Macmillan Foundations Series) (1st ed.). Springer.

Cite this articleas: Dip Mala Chapagain (2021). Power in international relations; with special referenceto soft power. International Journal of Political Science and Public A dministration. 1(1), 26-30. doi: 10.51483/ IJPSPA.1.1.2021.26-30. 